\title{
ASSESSMENT OF THE POTENTIALLY ALGICIDAL EFFECTS OF THYMUS SATUREIOIDES COSS. AND ARTEMISIA HERBA ALBA L. AGAINST MICROCYSTIS AERUGINOSA
}

\author{
TebaA, L. ${ }^{1}$ - Douma, M. ${ }^{1 *}$ - TAZART, Z. ${ }^{1}$ - MANAut, N. ${ }^{2}$ - Mouhri, K. H. ${ }^{1}$ - LOUdiki, M. ${ }^{1}$ \\ ${ }^{I}$ Department of Biology, Laboratory of Biology and Biotechnology of Microorganisms, Faculty \\ of Sciences Semlalia, Cadi Ayyad University of Marrakesh \\ P.O. Box 2390, Marrakesh, Morocco \\ ${ }^{2}$ Health and Environment Unit, Provincial Direction of the Ministry of National Education \\ Marrakesh, Morocco \\ *Corresponding author \\ e-mail:douma_mountasser@yahoo.fr; phone: +212-66-196-7057 \\ L. Tebaa and M. Douma equally contributed to the study. \\ (Received $18^{\text {th }}$ Sep 2017; accepted $15^{\text {th }}$ Jan 2018)
}

\begin{abstract}
In search of an ecofriendly algaecide, aqueous extracts of two medicinal plants, Thymus satureioides Coss. and Artemisia herba alba $\mathrm{L}$., were assessed for antialgal activity against Microcystis aeruginosa. An experiment was designed using five treatments ( $1 \%, 0.75 \%, 0.5 \%, 0.25 \%$ and $0.1 \%)$. The growth of M. aeruginosa, morphological modifications, and photosynthetic pigments (chlorophyll a and carotenoids) on exposure to the extracts were explored. Also, phytochemical parameters in the extracts were analyzed to reveal the potential allelochemical compounds.

The results showed that both $T$. satureioides and A. herba alba extracts inhibited the growth of $M$. aeruginosa in a concentration-dependent way. After 8 days of treatment, the highest inhibition rates reached were $95 \%, 93 \%$ and $88.58 \%$, and for T. satureioides and A. herba alba aqueous extracts, respectively. Chlorophyll a and carotenoid concentrations in cultures decreased especially in the $1 \%$ treatment group. Several morphological changes were observed in the treatment group compared to the controls. It was concluded that $M$. aeruginosa growth was suppressed by the potentially allelochemical compounds and probably by other allelochemical substances in aqueous extracts. Our results illustrated that both T. satureioides and A. herba alba extracts are able to control Microcystis blooms, and these may be recommended as a remedy for contamination of water bodies by harmful blooms.
\end{abstract}

Keywords: Microcystis aeruginosa, Thymus satureioides Coss., Artemisia herba alba L., algicides, morphological and physiological changes, inhibitory effect

\section{Introduction}

Cyanobacterial blooms are a major environmental problem in water bodies worldwide (Xiao et al., 2010). Their frequent appearance has been considered a consequence of eutrophication (Codd and Bell, 1985). Microcystis spp. are the most common bloom-forming cyanobacteria in eutrophic freshwaters (Douma et al., 2016; 2017). A break-out of Microcystis blooms releases cyanotoxins which can impair water quality, reduce productivity, decrease biodiversity, as well as causes severe illnesses to animals and humans (Rondel et al., 2008).

To control the adverse effects of cyanobacterial blooms, several strategies have been developed, often including the application of physical and chemical agents (Jeong et al., 2000). None of these methods can specifically control harmful algal blooms without causing secondary pollution or affecting aquatic organisms (Zhang et al., 2013). 
Therefore, there is an urgent need to develop safe algaecides for controlling these harmful algal blooms.

Recent researches have exploited plants as an alternative to chemical agents (Chen et al., 2012; Zhou et al., 2014; Meng et al., 2015; Li et al., 2016). Numerous studies have reported the inhibition of cyanobacterial biomasses by several aquatic plants such as Potamogeton maackianus (Wu et al., 2007), Myriophyllum spicatum (Zhu et al., 2010), Sagittariatrifolia (Li et al., 2016), and Eichhornia crassipes (Zhou et al., 2014). To explore the potential of terrestrial plant extracts for controlling cyanobacteria provide a new guide for developing algicide (Shao et al., 2013).

Terrestrial medicinal plants have shown positive bioactivity and have demonstrated antibacterial, antifungal, antiviral, and insecticidal properties. The most important bioactive constituents of plants are phenolic compounds (Chen et al., 2012; Zhang et al., 2013). However, there are few reports on the use of medicinal plants to control $M$. aeruginosa, notably Achillea ageratum $L$ and Origanum compactum Benth (Tebaa et al., 2017); Portulaca oleracea (Wang et al., 2016); Ailanthus altissima (Meng et al., 2015); Shaddock Peel, Pomegranate Peel (Wang et al., 2015).

In the Mediterranean area, medicinal plants are endemic (Bellakhdar, 1997). T. satureioides and $A$. herba alba are two well-known Moroccan medicinal plants (Ismaili et al., 2004; Bezza et al., 2010). Thymus is a Lamiaceae herbaceous species. It is a wellknown aromatic perennial herb used extensively throughout the Mediterranean basin (Ismaili et al., 2004). A wide range of biological and pharmacological properties, including antiseptic, anthelmintic, and anti-inflammatory activities, have been reported for these species (Elhabazi et al., 2008; Ichrak et al., 2011). Several reports have demonstrated their strong antimicrobial, insecticidal, antifungal, antiviral, and antioxidant properties due to the rich content of phenolic compounds such as thymol and carvacrol (Jamali et al., 2013).

A. herba alba, belonging to the family Asteraseae, has been used by the local population as a medicinal plant as well as a flavoring additive in tea and coffee (Bezza et al., 2010). It has been extensively used to treat stomach disorders, hepatitis, and certain poisoning cases, as well as an antitumor, antispasmodic, antiseptic, antigenotoxic, antidiabetic, and antibacterial agent (Bezza et al., 2010; Mighri et al., 2010).

Phytochemical components and secondary metabolites such as flavonoids and others phenolic compounds present in these make them attractive for medicinal uses (Mohamed et al., 2010). However, little information is available on the use of medicinal plants for the treatment of bloom-forming cyanobacterium $M$. aeruginosa ( $\mathrm{Ni}$ et al., 2011; 2012, Tebaa et al., 2017).

The aim of this study was to assess the potentially algicidal effects of $T$. satureioides and $A$. herba alba plants against $M$. aeruginosa with special attention to their photosynthetic pigments and allelochemicals compounds. To the best of our knowledge, this is the first report to study the impact of these two Moroccan specimens on Microcystis spp.

\section{Materials and methods}

\section{Algal and floral materials}

M. aeruginosa was isolated from the Moroccan eutrophic reservoir Lalla Takerkoust $\left(31^{\circ} 21^{\prime} 36^{\prime \prime} \mathrm{N} ; 8^{\circ} 7^{\prime} 48^{\prime \prime} \mathrm{W}\right)$ in October 2015. The isolated strain was grown in Z8 medium at $26 \pm 2{ }^{\circ} \mathrm{C}$ under light intensity of $40001 \mathrm{x} \cdot \mathrm{m}^{-2} \mathrm{~s}^{-1}$, with a light/dark cycle of 
$15 \mathrm{~h} / 9 \mathrm{~h}$. The cyanobacteria were cultivated to an exponential growth phase $\left(1-2 \times 10^{6}\right.$ cells $/ \mathrm{ml})$. The two medicinal plants $T$. satureioides and A. herba alba were collected in May 2016 from two locations, Oukaimden and Tahanaout (High Atlas, Marrakesh area). Specimens were botanically identified, confirmed, and deposited in the Herbarium Mark (Faculty of Sciences Semlalia, Cadi Ayyad University of Marrakesh). The aerial plant parts were rinsed several times with distilled water to remove debris and epiphytic microbes. Leaves were separated and conserved for further use.

\section{Preparation of aqueous extracts}

The aqueous extraction of plants was carried out according to the method described by Ball et al. (2001), slightly modified by Li et al. (2016). Briefly, 10g of leaves were cut into tiny pieces and placed in $100 \mathrm{ml}$ distilled water under agitation $\left(37^{\circ} \mathrm{C} ; 48 \mathrm{~h}\right)$. The macerate was filtered through a filter paper (Whatman $\mathrm{GF} / \mathrm{C}, 0.22 \mu \mathrm{m}$ ). Then the filtrate was adjusted with distilled water to $100 \mathrm{ml}$ and kept at $4^{\circ} \mathrm{C}$ as aqueous extract.

\section{Algal bioassay}

Experimental cultures were carried out in Erlenmeyer flask containing Z8 medium to a final volume $(300 \mathrm{~mL})$. Each flask was inoculated by a volume of $M$. aeruginosa in exponential growth phase to make an initial density $(1-2 \times 106$ cells $/ \mathrm{ml})$. Microcystis cultures were exposed to different concentrations ( $0 \%$ [control], $0.1 \%, 0.25 \%, 0.5 \%$, $0.75 \%, 1 \%$ ) of aqueous extract. The cultures were incubated in a culture room at $26 \pm 2^{\circ} \mathrm{C}$, illuminated in $15 \mathrm{~h} / 9 \mathrm{~h}$ light-dark cycle with fluorescent tubes $\left(40001 \mathrm{x} \cdot \mathrm{m}^{-2} \mathrm{~s}^{-1}\right)$. All experiments were carried out in triplicates.

\section{Biomass estimation}

$M$. aeruginosa growth under treatment was quantified through a daily sampling (every $24 \mathrm{~h}$ ) of a constant volume of culture $(2 \mathrm{ml}$ each replicate) using Malassez hemocytometer. Growth inhibitory rate (IR) of $M$. aeruginosa under different concentrations was determined according to Equation 1:

$$
\operatorname{IR}(\%)=(\mathrm{N} 0-\mathrm{N} / \mathrm{N} 0 \times 100,
$$

where $\mathrm{N} 0$ and $\mathrm{N}$ (cells/ml) are cell density in treatment and control cultures, respectively.

\section{Pigment quantification}

Chlorophyll-a and carotenoid concentrations were extracted in the dark with $95 \%$ ethanol at $4^{\circ} \mathrm{C}$ for $48 \mathrm{~h}$, and measured using a UV spectrophotometer (Carré $50 \mathrm{Scan}$ ) at 470, 649 and $665 \mathrm{~nm}$. Pigment quantification was calculated according to Lichthentaler and Wellburn (1983). The following formulas (Eq. 2 and 3) were used to calculate the concentrations:

$$
\begin{gathered}
\text { Chlorophyll-a }=13.95 \times \text { OD665 }-6.88 \times \text { OD649 } \\
\text { Carotenoids }=([(1000 \times \text { OD470) }-(2.05 \text { chlorophyll-a })]) / 2 \\
\text { APPLIED ECOLOGY AND ENVIRONMENTAL RESEARCH 16(1):903-912. } \\
\text { http://www.aloki.hu } \bullet \text { ISSN 1589 1623 (Print) } \bullet \text { ISSN 1785 0037 (Online) } \\
\text { DOI: http://dx.doi.org/10.15666/aeer/1601_903912 } \\
\text { @ 2018, ALÖKI Kft., Budapest, Hungary }
\end{gathered}
$$




\section{Determination of Total phenolic (TPs), Total flavonoids (TFs), Total tannins (TTs)}

TP concentration was determined using the Folin-Ciocalteu method (Singleton and Rossi, 1965). The total phenolic compounds were expressed as $\mu \mathrm{g}$ gallic acid equivalents per milliliter of aqueous extract.

TF concentration was determined by the method described by Kim et al. (2003). Measurements were calibrated to a standard curve of prepared catechin (Fluka) and the results were expressed as $\mu \mathrm{g}$ catechin equivalents per milliliter of aqueous extract. TT content was determined using the Folin-Denis test described by Salunkh et al. (1990), with slight modification. This method quantifies both condensed and hydrolysable tannins. A calibration curve was obtained using a tannic acid solution and the results were expressed as $\mu \mathrm{g}$ tannic acid equivalent per milliliter of aqueous extract.

\section{Statistical analysis}

The statistical significance between control and treatment groups was confirmed by analysis of variance (ANOVA) using SPSS V20.0 Windows 2010. Two-way ANOVA and Tukey's test were used to test differences between exposure concentrations and control at $\mathrm{p}=0.05$.

\section{Results}

\section{Inhibitory effects on M. aeruginosa}

As shown in Figure $1 A-B$ and Table 1, both T. satureioides and A. herba alba extracts exhibited a marked inhibitory effect on $M$. aeruginosa. In contrast to the control group, the cell densities of $M$. aeruginosa at all three concentrations $(0.5 \%, 0.75 \%$ and $1 \%$ ) for $T$. satureioides and A. herba alba extracts, respectively, were significantly reduced during the 8 -day test period $(\mathrm{p}<0.05)$. Moreover, the inhibition rates were dose-dependent within 8 days. For both T. satureioides coss and A. herba alba extracts, the maximum inhibition of cell growth $(94.46 \%, 94.60 \%$, and $95.93 \%$, and $88.58 \%$, respectively) was achieved at $0.5 \%, 0.75 \%$ and $1 \%$, and $1 \%$ concentrations, respectively. The results suggest that $T$. satureioides showed a strong inhibitory effect on algal cells, and the effective doses ranged from $0.5 \%$ to $1 \%$ (Fig. 1 C-D).

Table 1. Total phenolic (TPS), Total flavonoids (TFs), Total tannins (TTS) amounts in A. herba alba and T. satureioides LA extracts; and correlations between all amounts and IRs of the three high concentration $(0.5,0.75,1 \%)$ after 8 days of exposure

\begin{tabular}{c|c|c|c}
\hline & PT $^{1}$ & FT $^{2}$ & TT $^{3}$ \\
\hline Plant & \multicolumn{3}{|c}{ T. satureioides } \\
Concentrations & $285 \pm 34.82$ & $25.83 \pm 4$ & $0.032 \pm 0.002$ \\
Coefficient of correlation & -0.044 & -0.458 & $\mathbf{0 . 9 4 1}$ \\
\hline Plant & \multicolumn{3}{|c}{ herba alba } \\
Concentrations & $290 \pm 19.8$ & $37.61 \pm 0.66$ & $0.024 \pm 0.005$ \\
Coefficient of correlation & -0.999 & $\mathbf{0 . 5 3 6}$ & -0.215 \\
\hline
\end{tabular}

\footnotetext{
${ }_{1}^{1} \mu \mathrm{g}$ Gallic acid equivalent ml-1 Aqeous extract

${ }^{2} \mu \mathrm{g}$ catechin equivalent/ml Aqueous extract

${ }^{3} \mu \mathrm{g}$ tannic acid equivalents ml-1 Aqeous extract
} 


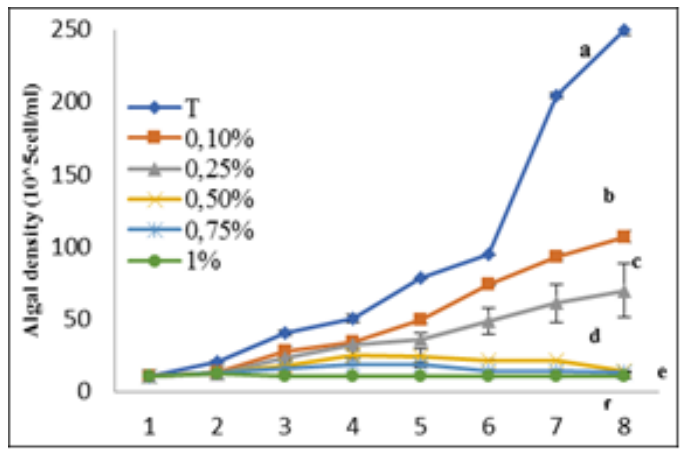

A

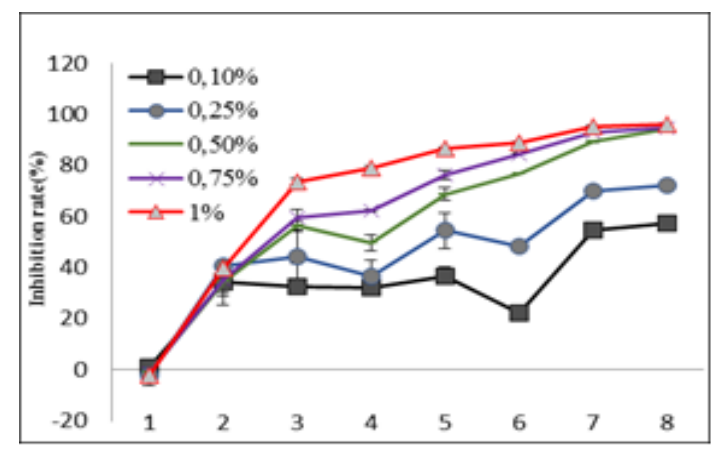

$\mathrm{C}$

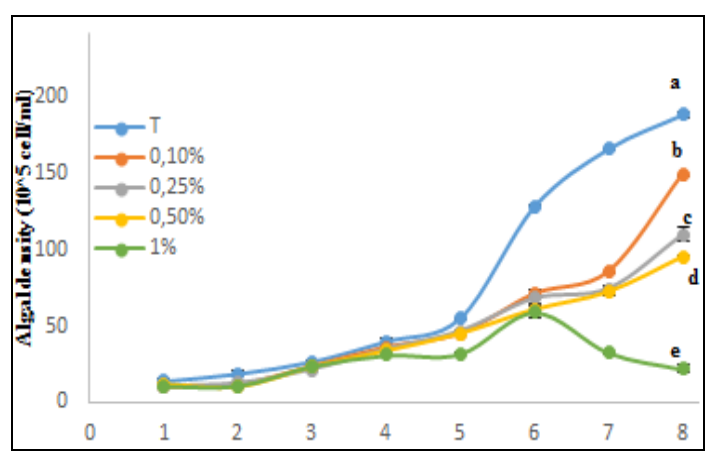

B

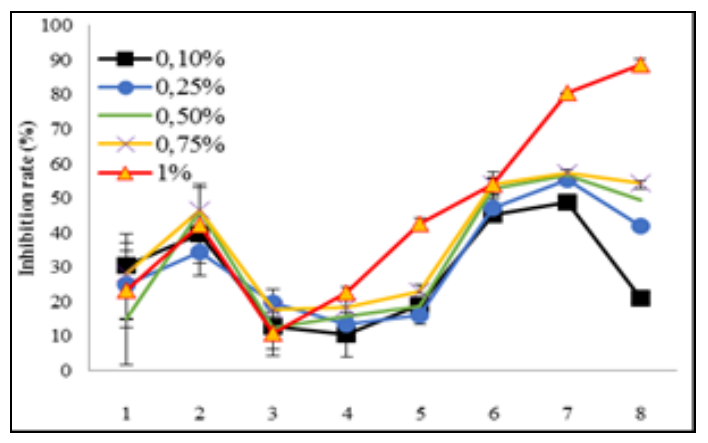

$\mathrm{D}$

Figure 1. Inhibitory effect of aqueous extracts of T. satureioides and A. herba alba on M. aeruginosa growth. A and B: density curves of $T$. satureioides, $A$. herba alba, respectively. $C$ and D: IR inhibition rate curves of T. satureioides, A. herba alba, respectively. The values are means \pm standard deviations calculated from different repetitions $(n=3)$. The value of $p<0.05$ was considered significant. Letters a to f: groups not sharing the same letter are significantly different means

\section{Effects on photosynthetic pigments}

The levels of two photosynthetic pigments (chlorophyll-a and carotenoids) were used as physiological indicators of the inhibition of Microcystis. In the control, the levels of both pigments increased as a function of tested concentrations (Fig. 2). Whereas in treatments, these globally decreased with the increase of concentrations. This demonstrated the significant difference between the treatment and control groups (p < 0.05) (Fig. 2). The levels of pigments appeared to be strongly inhibited at $95.93 \%$ and $88.58 \%$ concentrations of $T$. satureioides and A. herba alba, respectively.

\section{Inhibitory mechanism of plant extracts on M. aeruginosa}

According to the values of TPs, TFs, and TTs shown in Table 1, the concentrations in $T$. satureioides are higher than those in A. herba alba. As well, a significant correlation in IR was obtained between three significant concentrations $(0.5-1 \%)$ with regard to TT concentrations (coef $>0.8$ ) for $T$. satureioides sand with regard to $\mathrm{TF}$ concentrations (coef $>0.5$ ) for A. herba alba. 


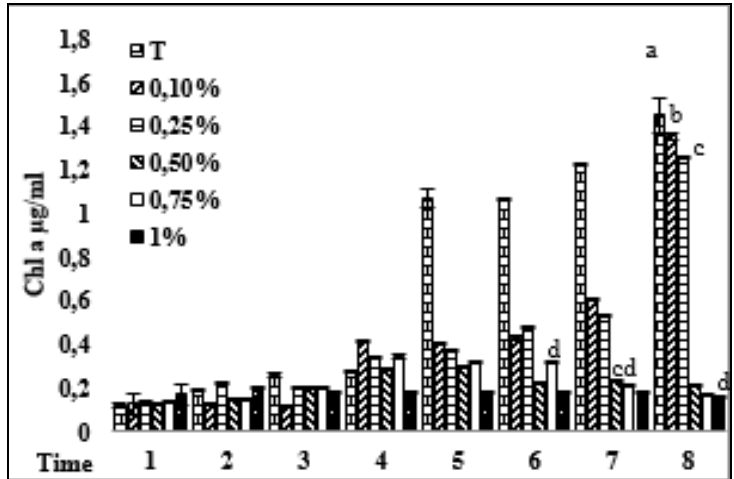

A

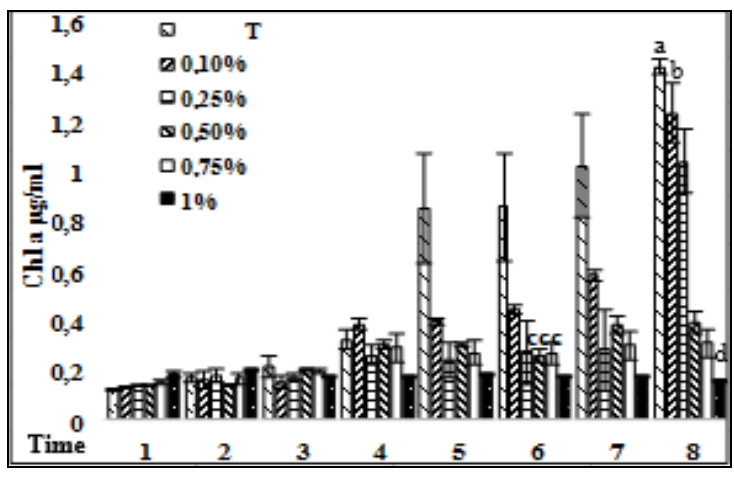

$\mathrm{C}$

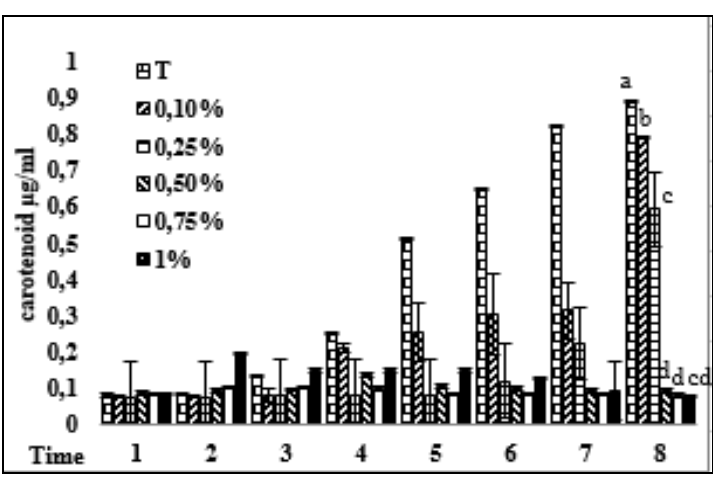

B

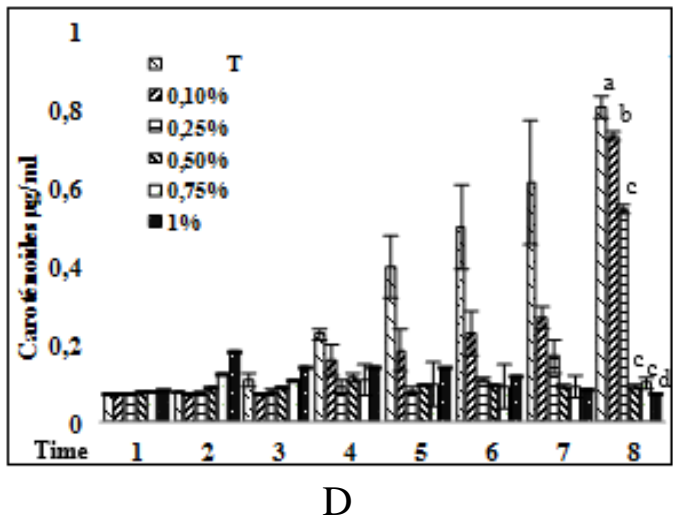

Figure 2. Effect of aqueous extracts on photosynthetic pigments of $M$. aeruginosa. A and $C$ : Contents of chlorophyll a of $T$. satureioide and A. herba alba, respectively. $B$ and $D$ :

Carotenoid contents of $T$. satureioides and A. herba alba, respectively

\section{Discussion}

According to this study, both A. herba alba and T. saturoides aqueous extracts had potential algicidal effects on Microcystis growth. They significantly reduced the biomass and photosynthetic pigments of $M$. aeruginosa.

After 7 days of treatment at $1 \%$ concentration, the maximum IRs of 95\%, 93\%, and $88.58 \%$ were reached using $T$. satureioides and A. herba alba aqueous extracts, respectively. Meng et al.(2015) demonstrated that A. altissima extracts showed an IR of $90 \%$ against $M$. aeruginosa while completely destroying the organelle responsible for photosynthesis in algal cells.

In a study by Li et al. (2016), S. trifolia tuber aqueous extract demonstrated the highest inhibition rate of $70 \%$ on $M$. aeruginosa after 6 days of treatment. Ye et al. (2014) studied several Chinese herb aqueous extracts on $M$. aeruginosa and obtained the maximum IRs in the range of $51-98 \%$ after 10 days. Besides, the lowest concentrations of aqueous extracts had only negligible inhibition effect on $M$. aeruginosa (Ye et al., 2014; Li et al., 2016). Similar trends were reported by Xiao et al. (2010).

On the other hand, T. saturoides at a concentration of $0.5 \%$ was sufficient to elicit a strong inhibition on the growth of $M$. aeruginosa. The difference between the present results and that of Nakai et al. (1999) might be explained by the importance of aerobic decomposition to generate more inhibitors for algal suppression (Li et al., 2016). 
For A. herba alba, only the concentration of $1 \%$ was significantly inhibitory compared to the controls, which suggests that the potentially bioactive substances inhibited the growth of $M$. aeruginosa. At all other concentrations $(0.1 \%, 0.25 \%, 0.5 \%$, $0.75 \%$ ), the growth retardation of $M$. aeruginosa was dose-dependent.

Furthermore, by microscopic observations, the presence of green color signified the abundant growth of $M$. aeruginosa in control cultures, whereas under treatments, the cultures became transparent with yellow sediment at the bottom after 6 days of treatment with $A$. herba alba (1\%) and $T$. saturoides $(0.5 \%, 0.75 \%$ and $1 \%)$ aqueous extracts (Fig. 3).

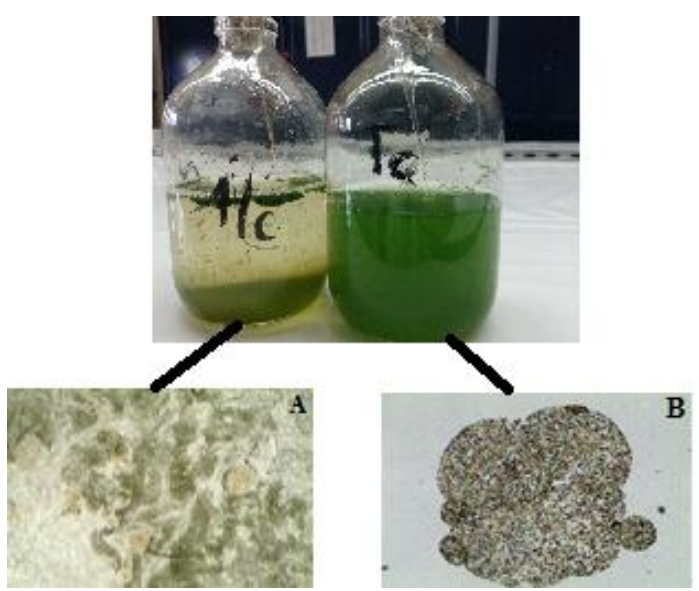

Figure 3. Microscopic observation of the behavior of M. aeruginosa in the concentration groups $1 \%$ of T. satureioides aqueous extracts. A: (Gr. $x$ 40) with sedimented cells, completely devacuolated and decomposed. B control group: ( Gr. x 40); with M. aeruginosa in normal growth

The results indicate that the extracts had a potential to accelerate $M$. aeruginosa cell lysis. These observations are in agreement with previous studies that investigated the cell morphology variations under treatments (Meng et al., 2015; Li et al., 2016). In our study, the photosynthetic pigments of M. aeruginosa were destroyed by aqueous extracts.

The antialgal allelochemicals reported in literature include fatty acids, polyphenols, terpenoids and polyethers. Previous studies have found that Myriophyllum spicatum releases four polyphenols and fatty acids that have an inhibitory effect on algae (Nakai et al., 2000).

In this study, tannins and flavonoids as potential allelochemicals made significant contribution to algal inhibition. These describe a group of phenolic compounds with a wide variety of allelochemical actions. Potential synergy between tannins and flavonoids may account for the maximum inhibition $95.93 \% \pm 0.49$ noted in $T$. satureioides.

Tannins have a toxic activity against filamentous fungi, yeasts, and bacteria, the antimicrobial activity of tannins could be due to their ability to form complexes with transport proteins (Scalbert, 1991). The inhibition of algal growth can be attributed to allelochemicals, including tannic acids. But because the correlation coefficient was less than 0.5 for $T$. saturoides, it is assumed that the phenolic compounds are one type among other secondary metabolites that cause algal inhibition (Chen et al., 2012). 
When investigating the antialgal activity of leaves of aquatic species Iris wilsoni on Microcystis sp., Whittaker and Feeny (1971) have shown that flavonoids, terpenoids, steroids, alkaloids, and organic cyanides are among allelochemicals to side polyphenolic compounds.

Chlorophyll-a and carotenoids are major pigments in microalgal photosynthetic systems (Yang et al., 2012). Their decrease shows the disturbance of photosynthesis affecting the growth and reproduction of $M$. aeruginosa (Li et al., 2016).

Allelopathic compounds behave like natural algicides; they often have multiple sites of action and various effects on the target organism (Ni et al., 2012). Some allelochemicals act by inhibiting photosynthesis, slowing down the growth of $M$. aeruginosa. They also attack the reactive oxygen species (ROS) on cell membranes by degrading unsaturated phospholipids and consequently increasing their permeability, leading to a disorder in cell organization (Meng et al., 2015).

The results of this study show that the use of these two plant extracts could bring great results in the biological control of harmful algae in aquatic ecosystems. However, further works will be needed to verify the application of these extracts in lakes for HAB inhibition. Also, it should be noted that the specific compounds responsible for such effects should be isolated and identified to explore the mechanism of inhibition in future studies and for field applications.

\section{Conclusion}

The present work demonstrated the inhibitory effect of aqueous extracts of $T$. satureioides and $A$. herba alba on $M$. aeruginosa growth. In addition to their antimicrobial, anti-inflammatory, analgesic, and antipyretic potentialities, these two medicinal plants can be used for ecofriendly restoration of aquatic environments contaminated by Microcystis blooms. Other future approaches will be necessary to optimize the allelochemical agents, as well as the conditions of interactions with other potential components, especially other pathogens, in the aquatic ecosystem.

\section{REFERENCES}

[1] Ball, A. S., Williams, M., Vincent, D., Robinson, J. (2001): Algal growth control by a barley straw extract. - Bioresource Technology 77(2): 177-181.

[2] Bellakhdar J. (1997): La pharmacopée marocaine traditionnelle. - Ibiss Press, Paris.

[3] Bezza, L., Mannarino, A., Fattarsi, K., Mikail, C., Abou, L., Hadji-Minaglou, F. Kaloustian, J. (2010): Chemical composition of the essential oil of Artemisia herba-alba issued from the district of Biskra (Algeria). - Phytotherapy 8(5): 277-281.

[4] Chen, J. Z., Zhang, H. Y., Han, Z. P., Ye, J. Y., Liu, Z. (2012): The influence of aquatic macrophytes on Microcystis aeruginosa growth. - Ecological Engineering 42: 130-282.

[5] Codd, G. A., Bell, S. G. (1985): Eutrophication and toxic cyanobacteria in fresh waters. Journal of Water Pollution Contrology 21: 1-13.

[6] Douma, M., Manaut, N., Oudra, B., Loudiki, M. (2016): First report of cyanobacterial diversity and microcystins in a Microcystis strain from a Mediterranean coastal lagoon (Sidi Boughaba, Morocco). - African Journal of Aquatic Science 41(4): 445-452.

[7] Douma, M., Ouahid, Y., Loudiki, M., del Campo, F. F., Oudra, B. (2017): The first detection of potentially toxic Microcystis strains in two Middle Atlas Mountains natural lakes (Morocco). - Environmental Monitoring and Assessment 189. DOI:10.1007/s10661-016-5753-x. 
[8] Elhabazi, K., Ouacherif, A., Laroubi, A., Aboufatima, R., Abbad, A., Benharref, A., Zyad, A., Chait, A., Dalal, A. (2008): Analgesic activity of three thyme species, Thymus satureioides, Thymus maroccanus and Thymus leptobotrys. - African Journal of Microbiology Research 2: 262-267.

[9] Ichrak, G., Rim, B., Loubna, A. S., Khalid, O., Abderrahmane, R., Saidel M. (2011): Chemical composition, antibacterial and antioxidant activities of the essential oils from Thymus satureioides and Thymus pallidus. - Natura. Product Communications 6(10): 1507-1510.

[10] Ismaili, H., Milella, L., Fkih-Tetouani, S., Ilidrissi, A., Camporese, A., Sosa S., Altinier, G., Della, L. R., Aquino, R. (2004): In vivo topical anti-inflammatory and in vitro antioxidant activities of two extracts of Thymus satureioides leaves. - Journal Ethnopharmacology 91(1): 31-36.

[11] Jamali, C. A., Kasrati, A., Bekkouche, K., Hassani, L., Wohlmuth, H., Leach, D., Abbad, A. (2013): Phenological changes to the chemical composition and biological activity of the essential oil from Moroccan endemic thyme (Thymus maroccanus Ball). -Industrial Crops and Products 49: 366-372.

[12] Jeong, J. H., Jin, H. J., Sohn, C. H., Suh, K. H., Hong, Y. K. (2000): Algicidal activity of the seaweed Corallinapilulifera against red tide microalgae. - Journal of Applied Phycology 12(1): 37-43.

[13] Kim, U. K., Jorgenson, E., Coon, H., Leppert, M., Risch, N. Drayna, D. (2003): Positional cloning of the human quantitative trait locus underlying taste sensitivity tophenyl thiocarbamide. - Science 299: 1221-1225.

[14] Li, J., Liu, Y., Zhang, P., Zeng, G., Cai, X., Liu, S., Yin, Y., Hu, X., Hu, X., Tan, X., (2016): Growth inhibition and oxidative damage of Microcystis aeruginosa induced by crude extract of Sagittariatrifolia tubers. - Journal of Environmental Sciences 43: 40-47.

[15] Lichtenthaler, H. K., Wellburn, R. R. (1983): Determination of total carotenoids and chlorophylls a and b of extracts in different solvents. - Biochemical Society Transactions 11(5): 591-592.

[16] Meng, P., Pei, H., Hu, W., Liu, Z., Li, X., Xu, H. (2015): Allelopathic effects of Ailanthus altissima extracts on Microcystis aeruginosa growth, physiological changes and microcystins release. - Chemosphere 141: 219-226.

[17] Mighri, H., Hajlaoui, H., Akrout, A., Najjaa H., Neffati, M. (2010): Antimicrobial and antioxidant activities of Artemisia herba-albaessential oil cultivated in Tunisian arid Zone. - Comptes Rendus Chimie 13(3): 380-386.

[18] Mohamed, A. H., El-Sayed, M. A, Hegazy, M. E, Helaly, S. E., Esmail, A. M., Mohamed, N. S (2010): Chemical constituents and biological activities of Artemisia herba alba. - Record of Natural Product 4(1): 1-25.

[19] Nakai, S., Inoue, Y., Hosomi, M., Murakami, A. (2000): Myriophyllum spicatum-released allelopathic polyphenols inhibiting growth of blue-green algae Microcystis aeruginosa. Water Research 34(11): 3026-3032.

[20] Nakai, S., Inoue, Y., Hosomi, M., Murakami, A. (1999): Growth inhibition of blue-green algae by allelopathic effects of macrophytes - Water Science and Technology 39(8): 4753.

[21] Ni, L., Acharya, K., Hao, X., Li, S., (2012): Isolation and identification of an anti-algal compound from Artemisia аппиа and mechanisms of inhibitory effect on algae. Chemosphere 88: 1051-1057.

[22] Ni, L. X., Hao, X. Y., Li, S. Y., Chen, S. J., Ren, G. X., Zhu, L. (2011): Inhibitory effects of different solvent extracts from three compositae plants on Cyanobacterium Microcystis aeruginosas. - Science China Chemistry 54: 1123-1129.

[23] Rondel, C., Arfi, R., Corbin, D., Le Bihan, F., Ndour, E. H., Lazzaro, X. (2008): A cyanobacterial bloom prevents fish trophic cascades. - Freshwater Biology 53: 637-651.

[24] Salunkh, D. K., Chavan, J. K., Kadam, S. S. (1990): Dietary Tannins: Consequences and Remedies. - CRC Press, Boca Raton. 
[25] Scalbert, A. (1991): Antimicrobial properties of tannins. - Phytochemistry 30: 38753883.

[26] Shao, J., Peng, L., Luo, S., Yu, G., Gu, J., Lin, S., Li, R. (2013): First report on the allelopathic effect of Tychonemabourrellyi (Cyanobacteria) against Microcystis aeruginosa (Cyanobacteria). - Journal of Applied Phycology 25: 1567-1573.

[27] Singleton, V. L., Rossi, J. A. (1965): Colorimetry of total phenolics with phosphomolybdicphosphotungstic acid reagents. - American Journal Enology and Viticulture 16: 144-158.

[28] Tebaa, L., Douma, M., Tazart, Z., Manaut, N., Mouhri, K., Loudiki, M. (2017): Algicidal effects of two medicinal plants extracts on Microcystis aeruginosa growth. - Applied Ecology and Environmental Research 15(4): 719-728.

[29] Wang, H., Zhang, L., Cheng, S., Liu, H., Liu, H. U., Sun., B. (2015): Composition of ethyl acetate extracts from three plant materials (shaddock peel, pomegranate peel, pomegranate seed) and their algicidal activities. - Polish Journal of Environmental Studies 24(4): 1803-1807.

[30] Wang, H., Zhang, L., Wang, Y. (2016): Isolating and Identifying Organic Acids from Portulacaoleracea and determining their Anti-cyanobacterial. A short Communication Polish Journal of Environmental Studies 26(1): 441-445.

[31] Whittaker R. H., Feeny P. P. (1971): Allelochemics: Chemical interactions between species. - Science 171(3973): 757-770.

[32] Wu, Z. B., Zhang, S. H., Wu, X. H., Cheng, S. P., He, F. (2007): Allelopathic interactions between Potamogeton maackianus and Microcystis aeruginosa. - Allelopathy Journal 20: 327-338.

[33] Wu, X., Wu, H., Chen, J. R., Ye, J. Y., 2013. Effects of allelochemical extracted from water lettuce (Pistia stratiotes Linn.) on the growth, microcystin production and release of Microcystis aeruginosa. - Environ. Sci. Pollut. Res. 20: 8192-8201.

[34] Xiao, X., Chen, Y., Liang, X., Lou, L., Tang, X. ( 2010): Effects of Tibetan hulless barley on bloom-forming cyanobacterium (Microcystis aeruginosa) measured by different physiological and morphologic parameters. - Chemosphere 81: 1118-1123.

[35] Yang, X. L., Deng, S. Q., De Philippis, R., Chen, L. Z., Hu, C. Z., Zhang, W. H., (2012): Chemical composition of volatile oil from Artemisia ordosica and its allelopathic effects on desert soil microalgae, Palmellococcus miniatus. - Plant Physiology and Biochemistry 51: $153-158$.

[36] Ye, L., Qian, J., Jin, S., Zuo, S., Mei, H., Ma, S. (2014): Algicidal effects of four Chinese herb extracts on bloom-forming Microcystis aeruginosa and Chlorella pyrenoidosa. Environmental Technology 35(9-12): 1150-1156.

[37] Zhang, C., Yi, Y. L., Hao, K., Liu, G. L., Wang, G. X. (2013): Algicidal activity of Salvia miltiorrhiza Bung on Microcystis aeruginosatowards identification of algicidal substance and determination of inhibition mechanism. - Chemosphere 93: 997-1004.

[38] Zhou, Q., Han, S., Yan, S., Guo, J., Song, W., Liu, G. (2014): Impacts of Eichhorniacrassipes (Mart.) Solms stress on the physiological characteristics, microcystin production and release of Microcystis aeruginosa. - Biochemical Systematics and Ecology 55: 148-155.

[39] Zhu, J. Y., Liu, B. Y., Wang, J., Gao, Y. N., Wu, Z. B. (2010): Study on the mechanism of allelopathic influence on cyanobacteria and chlorophytes by submerged macrophyte (Myriophyllum spicatum) and its secretion. - Aquatic Toxicology 98(2): 196-203. 